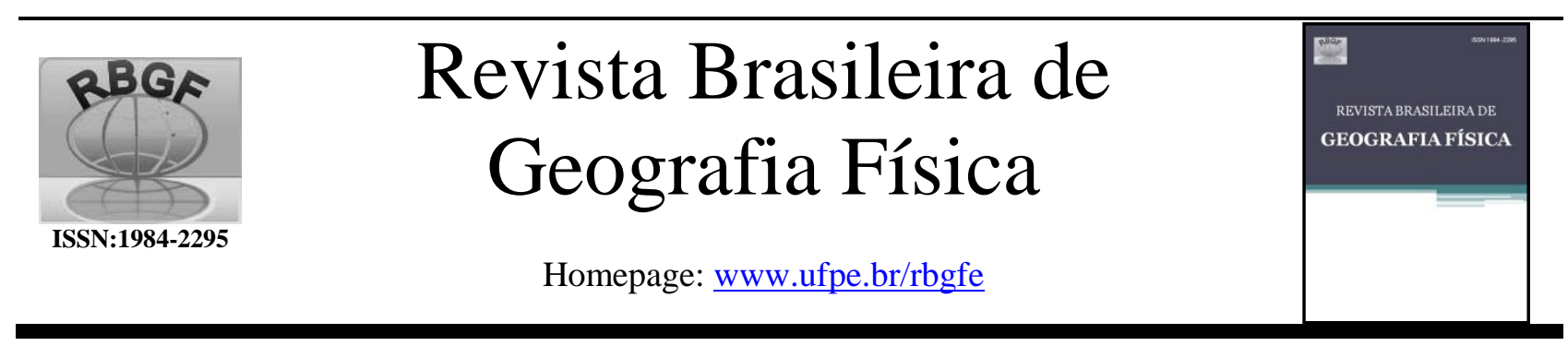

\title{
Participação Pública nos Processos de Licenciamento Ambiental no Triângulo Mineiro
}

\author{
Maria Rita Raimundo e Almeida. Universidade Federal de Itajubá. E-mail: maria.rita.ralmeida@ gmail.com \\ Pedro Vitor Silva Gonçalves. Universidade Federal de Uberlândia. E-mail: pedro_vitor94@ hotmail.com \\ Christyan Paiva Farias. Universidade Federal de Uberlândia. E-mail: christyanfarias@ hotmail.com
}

Artigo recebido em 02/02/2018 e aceito em 20/05/2018

\section{R E S U M O}

A participação pública no Licenciamento Ambiental (LA) apoiado em Avaliação de Impacto Ambiental é de extrema importância, tendo a função de envolver a comunidade nas tomadas de decisão, pois ela é afetada pelos impactos de um empreendimento. Assim, este estudo objetivou avaliar a participação nos processos de LA tramitados na Superintendência Regional de Regularização Ambiental do Triângulo Mineiro e Alto Paranaíba. Para isto, foi realizado um levantamento da realização da audiência pública nos processos entre 2009-2015 e a discussão de um estudo de caso, o processo de licenciamento da Vale Fertilizantes em Patrocínio/MG. Dos 79 processos de licenciamento que abriram edital para solicitação da audiência, apenas $18 \%$ tiveram a convocação da mesma. No caso analisado, percebeu-se uma intensa participação popular, mas que não resultou em nenhuma contribuição para o processo decisório. Assim, concluiu-se que a participação dentro do LA no Triângulo Mineiro ainda é frágil, necessitando de aperfeiçoamentos.

Palavras-chave: Avaliação de Impacto Ambiental, participação, audiência pública.

\section{Public participation in licensing processes in Triângulo Mineiro, Brazil}

\begin{abstract}
A B S T R A C T
Public participation in Environmental Licensing (EL) with Environmental Impact Assessment is extremely important, having the function of involving communities in decision making, as it is affected by impacts of a development. Thus, this study aimed to evaluate the participation in the EL processes processed in the Superintendência Regional de Regularização Ambiental do Triângulo Mineiro e Alto Paranaíba. For this, a survey of the public hearing was conducted in the cases between 2009-2015 and the discussion of a case study, Vale Fertilizantes' corrective licensing process in Patrocínio/MG. Of the 79 licensing processes that opened the notice to request the public hearing, only $18 \%$ had this event. In the case study analyzed, there was an intense population participation, but it did not result in any contribution to the decision-making process. Thus, it can be concluded that the participation within the EL is still fragile, in need of improvement.
\end{abstract}

Keywords: Environmental Impact Assessment, participation, public hearing.

\section{Introdução}

No Brasil, a Política Nacional do Meio Ambiente (PNMA), Lei Federal no 6.938 de 1981, tem como objetivo, entre outros, a compatibilização do desenvolvimento econômico e social com a preservação do meio ambiente, contando para este fim com instrumentos como o Licenciamento Ambiental (LA) e a Avaliação de Impacto Ambiental (AIA) (BRASIL, 1981).

O LA é o procedimento administrativo pelo qual o órgão ambiental competente licencia a localização, instalação, ampliação e a operação de empreendimentos e atividades poluidoras ou daquelas que, sob qualquer forma, possam causar degradação ambiental (CONAMA, 1997). Nos casos em que os empreendimentos e atividades poluidoras são capazes de causar significativa degradação ambiental, o processo de LA fica condicionado à realização da AIA. Neste contexto, a AIA compreende o processo de identificar, prever, avaliar e mitigar os efeitos relevantes de natureza biológica, física, social e outros efeitos de atividades ou projetos de desenvolvimento, antes que decisões importantes sejam tomadas (IAIA, 1999). Ela cumpre com seus objetivos ao desempenhar 4 papéis: ajudar à decisão; ajudar à concepção e planejamento de projetos; servir como instrumento de negociação social; e atuar como instrumento de gestão ambiental (Sánchez, 1993). 
Neste processo de avaliar as consequências ambientais de um empreendimento ou atividade, a AIA conta com diversas etapas, sendo a participação pública (PP) uma delas (Sánchez, 2008). A PP poderia contribuir com o processo de AIA em diversos momentos como na triagem, na preparação do escopo, durante a elaboração dos estudos de impacto ambiental, durante a análise do estudo por parte do órgão ambiental, além da etapa de monitoramento (Almeida e Montaño, 2015). Porém, no Brasil, essa participação é legalmente exigida somente após a conclusão do estudo de impactos, quando já existe um quadro completo da situação caso o empreendimento seja implantado (Sánchez, 2013).

A Resolução CONAMA no 09/1987 vem regulamentar a PP dentro do processo de AIA, sendo que a mesma deve ocorrer na forma de audiência pública (CONAMA, 1987). As audiências são eventos formais em que é realizado um debate aberto a todos sobre um determinado projeto e os impactos que o mesmo gera (Sánchez, 2013). A referida resolução vem apontar que a audiência pública deve acontecer nos casos de licenciamento apoiados na elaboração de Estudo de Impacto Ambiental e respectivo Relatório de Impacto Ambiental (EIA/Rima). Mesmos nestes casos, a audiência só irá acontecer se o órgão ambiental julgar necessário, ou quando for solicitada, após o edital comunicando a abertura do prazo de solicitação, por entidade civil, pelo Ministério Público, ou por 50 (cinquenta) ou mais cidadãos (CONAMA, 1987). Em outras palavras, só existe a obrigatoriedade da publicidade do processo com a possibilidade de solicitação e realização da audiência e participação pública, mas ela só acontecerá uma vez solicitada. Em Minas Gerais, a Deliberação Normativa do COPAM n ${ }^{\circ}$ 12/1994 (COPAM, 1994) reproduz o estabelecido na Resolução CONAMA nº 09/1987, sendo a legislação estadual que discorre sobre a realização das audiências nos processos de LA mineiros.

Em um contexto mundial, a participação pública está entre as principais deficiências dentro do processo de AIA, conforme aponta o levantamento de Morgan (2012). Nacionalmente, a situação se reproduz e a participação dentro do processo de AIA exerce, em grande parte, apenas um papel informativo ou consultivo, não colaborando e podendo não exercer sua influência na tomada de decisão (Almeida, 2013). Críticas também recaem sobre o fato da PP ocorrer na forma de audiência pública, sendo assim insuficiente para a população dar sua contribuição na decisão (Burian, 2006). Ainda, com esta conformação para a participação pública dentro da AIA brasileira, na maioria das vezes, ela delimita-se a expressar os posicionamentos da população, depois de ser informada sobre o empreendimento, tendo como esperança que isso afete de alguma forma a decisão a ser tomada pela autoridade competente (Sánchez, 2013).

Assim, o presente trabalho teve como finalidade avaliar a participação pública nos processos de LA que ocorreram no âmbito da Superintendência Regional de Regularização Ambiental do Triângulo Mineiro e Alto Paranaíba (SUPRAM TMAP) no estado de Minas Gerais (MG). Para isto, foi realizado um levantamento da realização da audiência pública nos processos de LA e a discussão de um estudo de caso, o processo de licenciamento da Vale Fertilizantes S.A. na cidade de Patrocínio/MG.

\section{Importância da Participação na Avaliação de Impactos Ambientais e sua Realidade}

Participar é fazer parte, tomar parte ou ter parte de algo (Bordenave, 1994). No plano dos tratados internacionais, existe um documento específico sobre participação pública, a Convenção de Aarhus, cidade dinamarquesa onde foi firmada, em 25 de junho de 1998. Esta convenção está assentada em três principais eixos: acesso a informação; a participação no processo decisório; e o acesso à justiça (Marcatto, 2005). No caso do LA apoiado em AIA, os três eixos se encaixam, pois, não pode haver a participação correta e verdadeira do público sem que se tenha acesso às informações relacionadas ao projeto, ficando suspensa a garantia de resultados sobre os questionamentos dos cidadãos nas tomadas de decisões.

Logo, a participação do público de alguma forma deve ser considerada tanto na realização adequada e justa de um governo democrático como nas atividades de tomada de decisão (Shepherd e Bowler, 1997) e, assim, como um componente fundamental do processo de AIA (Hartley e Wood, 2005).

A participação pública dentro da AIA pode ser anunciada como o abarcamento de pessoas e grupos que irão sofrer os efeitos benéficos ou maléficos de uma intervenção proposta como um projeto, um programa, um plano, uma política, que deve passar por um processo de decisão (IAIA, 1999). Ela é imprescindível, pois os empreendimentos que possuem capacidade de causar impactos significativos quase sempre afetam, degradam ou consomem os recursos ambientais que pertencem à sociedade, justificando dessa forma sua importância (Sánchez, 2013). Ainda, o envolvimento do público no processo de tomada de decisão é o fator mais importante na mudança de concepção do projeto (Kolhoff et al., 2009) e pode ajudar a garantir a abrangência, 
qualidade e eficácia da AIA, levando a melhores decisões (Glasson et al., 2005).

Neste sentido, Dias e Sánchez (1990) afirmam que a participação pública nos processos de implantação de empreendimentos tem várias funções e numerosos objetivos que auxiliam de diferentes e importantes formas na aprovação desses projetos, sendo capaz de revelar consequências de uma ação que não foram identificadas ou devidamente avaliadas através da aplicação de outras ferramentas de verificação, podendo contribuir então para aperfeiçoar pontos frágeis do estudo de impacto ambiental (EIA), fundamentando as decisões e permitindo que a população ao redor seja ouvida. Além disto, Ortolano (1997) destaca que a participação pública possibilita aos cidadãos a chance de se expressarem e de serem ouvidos, proporcionando a eles influenciar diretamente nos resultados da discussão. Com isso, ocorre o desenvolvimento de um mecanismo de comunicação entre 0 empreendedor e a população, onde o procedente fornece mais informações sobre o projeto, conversando junto com os responsáveis pela decisão, sobre as alternativas e impactos do projeto, esclarecendo também as preocupações do público.

O World Bank (1999) cita as seguintes vantagens da consulta pública: redução do número de conflitos e dos prazos de aprovação, gerando assim maior lucratividade para os investidores; governos melhoram os processos de decisão demonstrando maior transparência e responsabilidade; o público afetado pode influenciar $o$ projeto, existindo assim a possibilidade da redução de impactos adversos e maximização de benefícios; assegurar que se receba a compensação adequada; os planos de gestão são mais efetivos; há maiores possibilidades de que grupos vulneráveis recebam atenção especial, que questões de equidade sejam levadas em conta e que as necessidades dos pobres tenham prioridade.

A Internacional Association for Impact Assessment (IAIA, 1999) discorre que para tornar a participação dentro do processo de AIA algo confiável e aumentar o interesse e o afinco das partes envolvidas, ela deve seguir Princípios de Boas Práticas, mais especificamente, princípios operacionais e básicos. Os básicos devem ser introduzidos em toda AIA, onde ocorre a PP, desde o nível estratégico ao operacional, sendo eles: a PP adaptada ao contexto, ser informativa e pró-ativa, adaptável e comunicativa, inclusiva e equitativa, educativa, cooperativa e imputável. Os operacionais são como uma espécie de cartilha a se seguir, ou seja, como os princípios básicos devem ser aplicados às principais fases e atividades da avaliação de impactos. De acordo com eles, a PP deve ser: iniciada o mais cedo possível dentro do processo de AIA e sustentada, bem planejada e focalizada em questões negociáveis, apoiante dos participantes, diferenciada e otimizada, aberta e transparente, orientada para o contexto, credível e rigorosa.

Vasconcelos et al. (2010) reforçam a importância dos princípios internacionais de boas práticas, ao citar que a participação do público deve ocorrer o mais cedo possível, começando na préavaliação e continuar por todo o processo. Isto porque os vários estágios do processo de AIA fornecem oportunidades para o envolvimento dos diferentes atores (Devlin e Yap, 2008). É o que ocorre em países avançados com relação à AIA, onde a participação não só ocorre na tomada de decisão, mas em estágios anteriores como a triagem e o escopo (Morrison-Saunders e Early, 2008).

Assim, por toda a sua importância e capacidade de auxiliar, a participação deveria ocorrer em diversas etapas da AIA: na triagem; na preparação do escopo, onde, segundo Hokkanen e Jantunen (2012), ela é crucial para sua qualidade e da AIA como um todo; durante a elaboração dos estudos de impacto ambiental, onde diagnósticos ambientais elaborados unicamente com base no conhecimento cientifico formal podem passar ao largo de questões relevantes não somente para as próprias comunidades (Sanchez, 2008); na análise do estudo por parte do órgão ambiental, além da etapa de monitoramento. Nesta última etapa, o envolvimento público é recomendado, pois lhe confere a oportunidade de participar da verificação dos resultados nos estágios finais do processo (Soneryd, 2004).

Apesar de toda a sua relevância, em uma pesquisa realizada para avaliar o estado da arte da AIA em vários países foram encontradas diversas limitações neste processo e dentre os problemas principais identificados estavam àqueles relacionados à participação (Morgan, 2012), seja por não ser efetiva e capaz de influenciar a tomada de decisão (Pardo; 1997; Furia e Wallace-Jones, 2000; Almer e Koontz, 2004; Soneryd, 2004; Nadeem e Hameed 2008; Panigrahi e Amirapu, 2012; Pope et al., 2013), por possuir apenas um papel meramente informativo ou consultivo (Cortner, 2000; Soneryd, 2004) ou por acontecer tardiamente no processo e prejudicar a formulação de alternativas locacionais e tecnológicas (Steinemann, 2001). Para Hartey e Wood (2005), estiveram entre as principais barreiras para uma participação efetiva o pobre fornecimento de informações, a fraca influência na tomada de 
decisão e a deficiência na execução de metodologias participativas.

No contexto brasileiro, a participação pública nos processos de avaliação de impacto ambiental é também deficiente, pois favorece uma dinâmica com um clima de confronto, e esse embate, como Sánchez (2013) aponta, é levado para um jogo de soma nula, porque nenhuma das partes consegue chegar a um ponto comum. Logo, pode-se dizer que a PP na AIA apresenta meramente um papel informativo ou consultivo (Almeida, 2013). Além disso, essa etapa ocorre tardiamente no processo de AIA, onde demais decisões de suma importância já foram tomadas; e a maior parte do público dispõe de pouca informação e, portanto, grande parte não tem condições de decodificar e compreender o parecer de caráter técnico e científico que é colocado (Sánchez, 2013).

Em 2004, o Ministério Público Federal (MPF, 2004) fez um estudo apontando as principais deficiências da AIA brasileira, mais especificamente relacionada à elaboração dos estudos ambientais. Dentre elas, as que afetam diretamente a participação pública nas audiências são as relacionadas ao Relatório de Impacto Ambiental (Rima), sendo elas: o Rima não contém todas as informações necessárias para a população (incompleto), distorção de resultados do Estudo de Impacto Ambiental (EIA), no sentido de minorar os impactos negativos e o emprego de uma linguagem não compreensível à população (uso de termos técnicos). A questão da linguagem dos Rimas já havia sido apontada por Ronza (1998) ao analisar processos concluídos pela Companhia de Tecnologia de Saneamento Ambiental (CETESB), entre janeiro de 1987 e dezembro de 1997, onde este tipo de estudo não apresentava uma linguagem acessível à comunidade (grande presença de termos técnicos), limitando assim a participação pública. Ainda, conforme aponta Burian (2006), a PP na forma de audiência pública é insuficiente para garantir a contribuição da comunidade no processo de licenciamento ambiental, pois os indivíduos têm acesso ao EIA/Rima momentos antes da audiência. Realidade semelhante e mais atual também foi encontrada por Almeida (2013).

Assim, a PP, em muitos casos, não passa de um cumprimento burocrático, ou seja, ela é feita apenas para respeitar o que a lei exige, mas sem apresentar o seu caráter de instrumento de apoio da AIA.

\section{Material e métodos}

Levantamento dos Processos de Licenciamento foram submetidos à análise neste trabalho os processos de licenciamento ambiental baseados em
AIA com elaboração de EIA/Rima submetidos a SUPRAM TMAP, entre os anos de 2009 (01/01/2009) a 2015 (31/12/2015). Como o órgão ambiental mineiro não faz em seu sistema uma diferenciação dos processos de licenciamento por terem sido objetos de análise através de EIA/Rima, para o levantamento dos processos foi necessário recorrer à obrigatoriedade das publicações informativas de abertura dos processos e do prazo para a solicitação da audiência presentes no Diário Oficial do Estado de Minas Gerais (DOE-MG), conforme regem a Resolução CONAMA $\mathrm{n}^{\circ}$ 09/1987 e a Deliberação Normativa do COPAM n ${ }^{\circ}$ 12/1994. Assim, a pesquisa no DOE-MG teve duas fases: uma para levantamento dos processos de licenciamento apoiados em EIA/Rima e que, portanto, poderiam ter a realização da audiência, e outra dos processos onde foi realizada a audiência pública.

Para o primeiro levantamento, no momento da busca através da página eletrônica do DOE-MG (http://www.iof.mg.gov.br/index.php?/pesquisanos-jornais.html) foram utilizados os termos "O Conselho Estadual de Política Ambiental COPAM", restringindo a pesquisa para o Diário Executivo. Já para o segundo levantamento, na busca foram utilizados os termos "Edital de convocação de audiência pública sobre o", também restringindo a pesquisa para o Diário Executivo. A partir dos resultados destas buscas, foram filtrados aqueles que se referiam a abertura de processos de licenciamento ou a realização de audiência pública no âmbito da Supram TMAP. Os termos de busca foram selecionados por fazerem parte do texto padrão para a publicação adotado pelo órgão ambiental.

Dos processos de licenciamento com participação levantados foi escolhido como estudo de caso aquele que se referia ao empreendimento da Vale Fertilizantes, localizado no município de Patrocínio. A escolha baseou-se no fato de ser um processo de licenciamento corretivo, ou seja, de empreendimentos que se instalaram e/ou estão em operação sem a devida licença ambiental, onde o alcance da participação pode ficar ainda mais reduzido, uma vez que a ação geradora do impacto já foi concretizada, mostrando-se, assim, como um caso interessante de análise.

Estudo de Caso - o empreendimento em questão da Vale Fertilizantes já havia sido licenciado ambientalmente, ocasião onde foi apresentado o EIA/Rima em agosto de 2000, tendo uma licença prévia concedida em 11/03/2004 com validade até 11/03/2008. Em seguida, a empresa obteve a licença de instalação com validade até 14/05/2014. Em janeiro de 2014, a empresa solicitou a 
prorrogação de prazo por mais dois anos para a instalação do empreendimento, tendo como justificativa o cenário da economia atual e do mercado de fertilizantes, além de restrições de acesso a algumas propriedades, pois estavam em processo de negociação assistida. Assim, a licença de instalação foi prorrogada por mais dois anos, tendo validade até 14/05/2016. No entanto, em janeiro de 2015, a Vale formalizou um novo EIA/Rima junto ao órgão ambiental, tendo como objetivo obter uma licença de instalação corretiva (LIC) para este empreendimento, uma vez que o projeto original tinha sofrido alterações substanciais. Ainda, em agosto do mesmo ano, a empresa efetivou uma alteração no EIA/Rima, apresentando um informativo sobre a otimização do projeto, diminuindo a Área Diretamente Afetada de 1.014,94 hectares para 558,41 hectares, ou seja, uma redução de 55\% da área inicialmente determinada.

Assim, o estudo de caso deste trabalho é o processo administrativo $\mathrm{n}^{\circ} 17414 / 2007 / 007 / 2015$, onde a Vale Fertilizantes requereu uma licença de instalação corretiva (LIC) para as atividades listadas: lavra a céu aberto com ou sem tratamento a seco de minerais não metálicos, exceto em áreas cársticas ou rochas ornamentais e de revestimento, pilhas de rejeito/estéril com área de 104,58 hectares, sendo classificado na classe 6 de acordo com a Deliberação Normativa do COPAM $n^{\circ}$ 74/2004. As demais atividades destinadas à exploração da jazida localizada em Patrocínio MG contemplam: obras de infraestrutura (pátios de resíduos, produtos e oficinas) com área útil de 5,0 hectares, estradas para transporte de minério/estéril com 16,5 km, ferrovias - ramal, terminal de minério, correias transportadoras, subestação de energia elétrica, canais para drenagem, retificação de cursos d'água, tratamento de esgoto (uma estação de tratamento de efluentes será construída na área de apoio à mina e uma estação de tratamento de efluentes oleosos para as instalações de apoio), posto de abastecimento, aterro para resíduos não perigosos - classe II e depósito de sucata metálica, papel, papelão, plástico ou vidro para reciclagem, contaminados com óleos, graxas ou produtos químicos, exceto embalagens de agrotóxicos (aterro sanitário de uso exclusivo do Complexo Mineral de Patrocínio para a disposição final dos resíduos de classe II e II-B gerados no empreendimento).

No dia 20/09/2015, a equipe da SUPRAM TMAP vistoriou toda a área destinada ao empreendimento e, com o protocolo do EIA/Rima, uma audiência pública foi solicitada e é esta participação que foi analisada no presente estudo.
Análise do Estudo de Caso - a busca por informações e questões referentes à participação pública no estudo de caso foi feita no órgão ambiental competente, SUPRAM-TMAP, com sede na cidade de Uberlândia/MG, por meio de vistas aos documentos componentes do processo de licenciamento ambiental. Alguns dias após solicitar vistas ao processo ao órgão ambiental, o material solicitado foi disponibilizado por meio de um DVD contendo todos os documentos componentes do referido processo de licenciamento.

Após realizar uma busca por informação nos documentos componentes do processo do empreendimento em questão, foram levantadas e analisadas as seguintes informações e/ou documentos: agente solicitante da realização da audiência pública; ata da audiência pública; número de pessoas que participaram da audiência; número de pessoas que se inscreveram para participar (falar) da audiência; pedidos de informações complementares por parte da SUPRAM TMAP, antes e após a realização da audiência; e parecer final do corpo técnico. Estas informações foram analisadas de forma a verificar a contribuição que a audiência pública trouxe para o processo de licenciamento, principalmente, se a audiência resultou na solicitação de alguma informação complementar por parte do órgão ambiental que possa ter contribuído com o processo de tomada de decisão.

\section{Resultados e discussão}

Visão Geral da Participação nos Processos de Licenciamento - com o intuito de organizar as informações levantadas, os empreendimentos e/ou atividades foram divididos de acordo com as listagens de atividades presentes na Deliberação Normativa do COPAM n ${ }^{\circ}$ 74/2004: Atividades Minerárias; Atividades Industriais/Indústria Metalúrgica e Outras; Atividades Industriais/Indústria Química; Atividades Industriais/ Indústria Alimentícia; Atividades de Infraestrutura; Serviços e Comércio Atacadista; e Atividades Agrossilvipastoris.

No recorte de tempo analisado (20092015), houve comunicação da abertura de prazo para a solicitação da audiência pública de 79 empreendimentos, ou seja, 79 empreendimentos basearam seu processo de licenciamento ambiental em AIA com a elaboração de EIA/Rima. Desse total, apenas 14 tiveram a realização da audiência pública em seu processo de licenciamento ambiental, tendo, portanto, ocorrido uma AIA com alguma forma de participação. A Figura 1 apresenta os levantamentos numéricos realizados. 


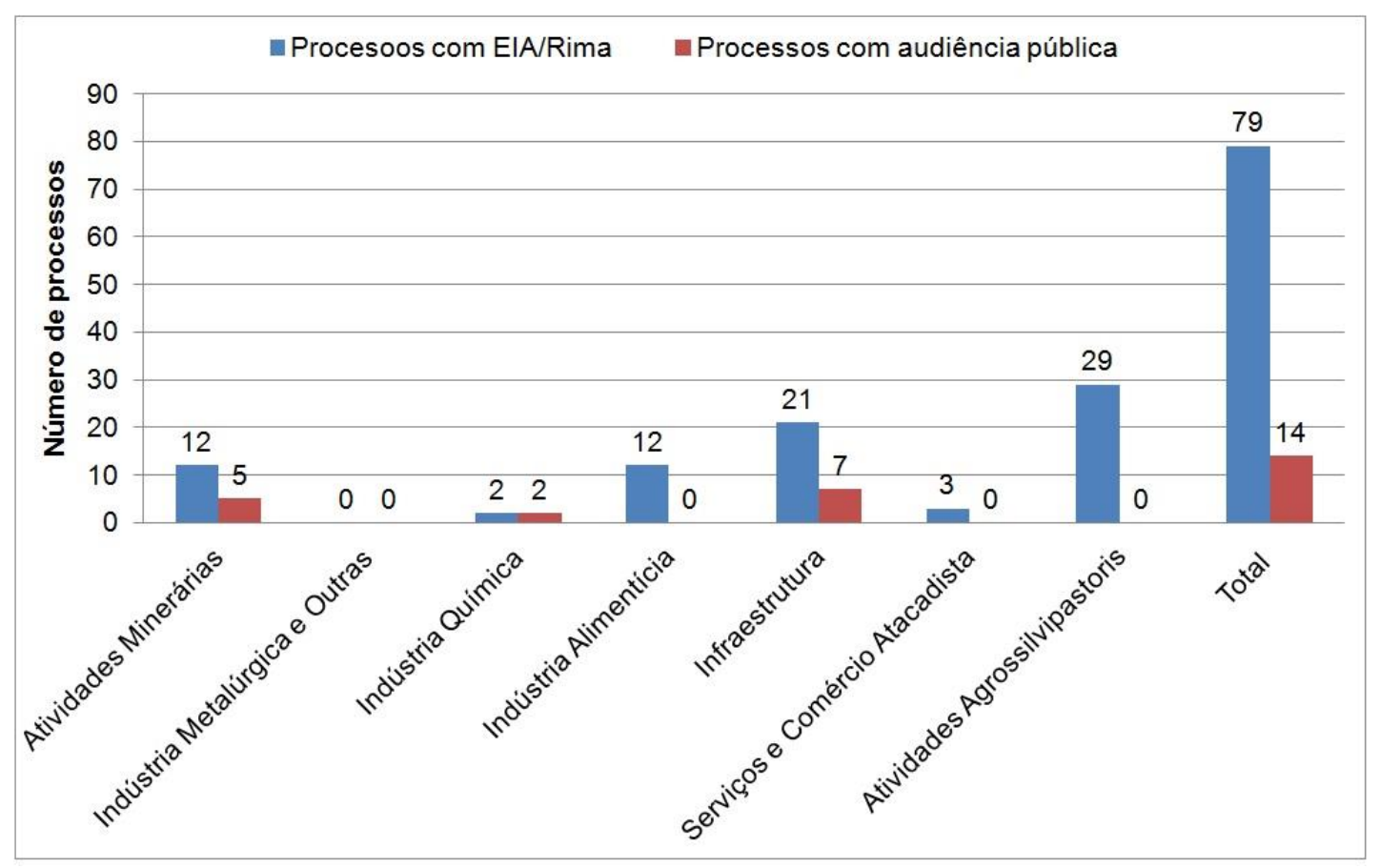

Figura 1: Levantamento dos processos de licenciamento baseados na elaboração de EIA/Rima

Conforme as informações da Figura 1, dos processos de licenciamento ambiental apoiados em EIA/Rima menos de $18 \%$ tiveram participação através da audiência pública. Este baixo número pode ser justificado pelo fato de que, em Minas Gerais, desde dada a devida publicidade, a figura desse evento é facultativa. Diferente do que ocorre em outros órgãos competentes pelo licenciamento, como o caso da Companhia Ambiental do Estado de São Paulo (CETESB), a audiência pública nos processos de licenciamento só ocorre caso algum ator, que não o órgão ambiental, solicite. Em outras palavras, o órgão ambiental mineiro entende que se a audiência não foi solicitada pelos interessados (entidade civil, Ministério Público e 50 ou mais cidadãos), ele mesmo não faz esta solicitação. Uma vez que existe a publicidade do período de solicitação de audiência, o que pesa mais é a falta de envolvimento da sociedade com as questões ambientais e a baixa cultura de processos participativos.

Situação semelhante foi encontrada por Almeida (2013) ao analisar a participação dentro do processo de licenciamento com AIA no âmbito da Supram Sul de Minas: apesar de ter havido o cumprimento dos requisitos legais, a participação não ocorreu nas etapas anteriores à análise técnica e, mesmo nesta fase, aconteceu, sob a forma de audiência pública, em poucos casos (4 em um total de 17 casos avaliados). Este fato sugere que a deficiência da AIA ocorrer sem a participação, não é exclusiva da regional TMAP, mas pode ser uma situação que ocorre no estado de Minas Gerais como um todo. Logo, é pertinente refletir que uma participação pública efetiva necessita de novas formas de informação e envolvimento (Partidário e Sheate, 2013).

De acordo com Constituição Federal Brasileira de 1988 (BRASIL, 1988), é dever do cidadão brasileiro "ter atitudes que ajudem na preservação do meio ambiente e dos recursos naturais". A população deveria ter um maior interesse em saber o que a atividade a ser instalada traria de benefícios e malefícios, pois, como já relatado anteriormente, os empreendimentos que possuem capacidade de causar impactos significativos quase sempre afetam, degradam ou consomem os recursos ambientais que pertencem à sociedade (Sánchez, 2013). Mais que um dever, a participação na AIA consiste em um direito da população. No entanto, como mostrou os dados do panorama geral de realização de audiência pública, a PP na AIA no Triângulo Mineiro ainda encontra um baixo nível de envolvimento da população.

Estudo de Caso: Participação no Processo de Licenciamento Ambiental da Vale Fertilizantes - a seguir são apresentados e discutidos os resultados da análise da participação pública no processo administrativo referente à licença de instalação corretiva (LIC) que tramita na Superintendência Regional de Meio Ambiente Triângulo Mineiro e Alto Paranaíba (SUPRAMTMAP) sob o $\mathrm{n}^{\mathrm{o}} 17414 / 2007 / 007 / 2015$, cujo 
empreendimento é de responsabilidade da Vale Fertilizantes com localização na cidade de Patrocínio/MG. Todas as informações apresentadas estão contidas nos documentos que compõe o referido processo de licenciamento.

Após o protocolo do EIA/Rima e a devida publicidade, a audiência pública foi solicitada por quatro órgãos: pela Ação Franciscana de Ecologia e Solidariedade, pelo Conselho de Desenvolvimento Comunitário de Santo Antônio da Lagoa Seca, pelo Fórum Nacional das Sociedades Civis nos Comitês de Bacias Hidrográficas e pela Promotoria Pública de Minas Gerais, representada pelo promotor da Comarca de Patrocínio.

O EIA/Rima do empreendimento foi disponibilizado a partir do dia 01/09/2015 até a data da audiência (20/09), estando cópias disponíveis para consulta na Prefeitura de Patrocínio, na Câmara Municipal de Patrocínio, na Vale Fertilizantes e no Centro Universitário do Cerrado Patrocínio (UNICERP). No decorrer da audiência, ele também estava disponível para consulta no salão do evento. Algo que chamou a atenção com relação ao processo foi a quantidade de pessoas que consultaram o EIA/Rima, sendo um total de 707, conforme consta na lista de presença de consulta dos diferentes locais de disponibilização do estudo.

Antes da audiência pública, foram feitas reuniões prévias com a população e seus representantes, em um total de 25 , tanto na cidade de Patrocínio como em outras cidades e comunidades vizinhas que serão afetadas de forma direta ou indireta, com o intuito de explicar o empreendimento. No entanto, os documentos que compunham o processo não apresentavam mais informações sobre estas reuniões.

Já focando na audiência, esta teve uma ampla divulgação, tendo o uso de várias mídias, dentre elas: anúncios em jornais, rádios e internet, convites impressos e eletrônicos, cartazes, folhetos, faixas e carro de som.

Para o deslocamento até a audiência, a prefeitura de Patrocínio disponibilizou transporte público para a população. Assim, no dia 30/09/2015, às 19h, no Catiguá Tênis Clube, acesso pela Av. Faria Pereira, s/n ${ }^{\circ}$, Centro, em Patrocínio - MG, teve início a audiência pública relacionada ao processo em questão, que durou até as $23 \mathrm{~h} 11$. Os números oficiais da SUPRAM apontam que na audiência pública estavam presentes 665 pessoas. Mas, considerando o local de realização do evento (700 assentos disponibilizados) e considerando que algumas pessoas ficaram de pé, certamente o número de pessoas presentes na audiência pública superou o número de inscritos. Acredita-se, então, que a audiência tenha tido um público em torno de 800 a 900 participantes. Dos inscritos para se manifestar, 5 eram autoridades, 29 cidadãos, 16 representantes da Sociedade Civil Organizada, 1 membro do COPAM, 6 membros do poder Legislativo e 4 membros do poder Executivo.

Todas as pessoas que se inscreveram para falar tiveram seu tempo e espaço respeitados, sendo que alguns inscritos preferiram não mais se manifestar. Conforme as normas da audiência, o representante da Vale Fertilizantes falou por 10 minutos; o integrante da equipe responsável pela elaboração do EIA/Rima teve 30 minutos; as quatro pessoas solicitantes da audiência tiveram um prazo de 7 minutos e 30 segundos para dar o seu posicionamento em relação ao empreendimento; as entidades civis com 16 participantes, tendo 5 minutos para fala de cada um; os integrantes do Poder Legislativo, sendo 5 membros (1 membro abriu mão da fala), que também tiveram o tempo de 5 minutos de fala para cada um; e, por último, mais quatro pessoas inscritas, o prefeito de Patrocínio, secretários de estado e de município que tiveram o prazo de 5 minutos. Ao final, o representante do empreendimento teve mais 10 minutos para falar e os quatro membros solicitantes da audiência tiveram um prazo de mais dois minutos e meio cada um para as considerações finais e resposta às indagações levantadas. A ata da audiência, com 107 páginas, reproduz fielmente a fala de todas estas pessoas. Alguns pontos principais levantados foram:

- comunidades tradicionais sendo expulsas de suas terras;

- a cidade de Patrocínio ficará somente com o processo de lavra ("só cavar o buraco"), sendo que a parte industrial será feita na cidade de Araxá. Com isso, a quantidade de emprego diminuiu de 5000 empregos para 600;

- o EIA/Rima não foi elaborado em relação ao empreendimento como um todo, sendo contemplada apenas a estrutura a ser implantada no município de Patrocínio, sem considerar os impactos do transporte de material entre as cidades de Patrocínio e Araxá;

- questionou-se o benefício que o empreendimento deixaria para a cidade;

- o tamanho da área disponibilizada seria maior do que a empresa realmente precisaria, uma vez que a empresa não mais faria a parte industrial no local;

- discutiu-se questões referentes ao mecanismos de compensação ambiental prevista pela lei do Sistema Nacional de Unidade de Conservação (SNUC); 
- e, por fim, a questão mais questionada, que diz respeito a uma grande demora na liberação das novas áreas para as populações que foram realocadas. Para este novo local de habitação, a população requer melhorias para que possa receber a todos os deslocados.

Com os esclarecimentos da audiência e demais informações do processo, pode-se descrever o projeto proposto para o deslocamento e realocação das pessoas. $\mathrm{O}$ processo de indenização assistida para as famílias residentes no local do empreendimento teve início em outubro de 2011 e foram divididos em três opções de atendimento: Reassentamento, Indenização Assistida (permutas) e Indenização Simples (vendas). O Reassentamento envolve 10 propriedades em que os proprietários aceitaram ir para a área anfitriã (Fazenda Irmãos Matos) a ser implantada pela Vale Fertilizantes S/A (infraestrutura e benfeitorias). A Indenização Assistida (permutas) conta com 31 propriedades em que os proprietários optaram por permutas de propriedades e que necessitam de assistência técnica para manutenção da produtividade e condições econômicas. E a Indenização Simples (vendas) trata de 5 propriedades em que os proprietários não optaram pelas opções anteriores e pretendem simplesmente vender suas propriedades.

No reassentamento, com o intuito de viabilizar a atender as demandas da comunidade, a empresa aprimorou sua proposta de permuta numa relação de troca de ordem 1,0 ha x 3,0 ha em área total, além de garantias como reposição de moradias, instalações produtivas, infraestrutura e regularização de documentos (com reservas legais, áreas de proteção permanente e outorga para captação de água). Ainda, é importante ressaltar que os equipamentos sociais (Igreja e Centro Comunitário) instalados na comunidade da Mata da Bananeira, serão repostos pela Vale Fertilizantes S/A na área anfitriã (Fazenda Irmãos Matos) e também em área não afetada pelo Complexo Minerador de Patrocínio, próximo a comunidade Mata da Bananeira, sendo que a definição do local de reposição já se encontra em definição pela comunidade, Diocese e empresa.

$\mathrm{Na}$ indenização Assistida, foram prospectadas várias propriedades nos municípios de Patrocínio, Serra do Salitre e Cruzeiro da Fortaleza para permutas, mas elas não se equipararam ao potencial produtivo $\mathrm{e}$ caracterizações quando comparadas as áreas dos proprietários da Mata da Bananeira, interessados pela indenização assistida. Assim como no Reassentamento, as propriedades serão entregues regularizadas ambientalmente, com reservas legais, área de preservação permanente e outorgas.

A indenização simples das 5 famílias que optaram pela simples venda das propriedades está ocorrendo paralelamente ao processo da indenização assistida e todas elas já foram visitadas e informadas que caso as áreas apresentadas para a permuta da opção de indenização assistida despertem interesse, é possível mudança de opção - algumas famílias optaram por essa alteração.

Para as populações que tiveram de ser realocadas, foi criado um Programa de Atendimento Psicossocial, que tem por objetivo apoiar as famílias na busca da superação de suas fragilidades, carências e necessidades identificadas no decorrer das negociações e realocação involuntária. Além disso, algumas atividades serão realizadas como, por exemplo, visitas domiciliares, atendimentos terapêuticos em grupo e encaminhamento para psicoterapia individual. Dinâmicas em grupo que possuam temas diversos serão aplicadas, podendo ser direcionadas a grupos específicos (mulheres e crianças).

Uma vez levantadas todas as questões discutidas na audiência, em um segundo momento, buscou-se verificar se este intenso envolvimento da população em termos numéricos na audiência resultou em alguma contribuição para o processo. A possibilidade de contribuição analisada foi o pedido de informações complementares (IC), em função das questões levantadas pela audiência. A princípio, após a audiência pública, a SUPRAMTMAP solicitou uma série de informações complementares com o intuito de esclarecer questões para a finalização de sua análise a respeito da viabilidade ambiental do empreendimento. No entanto, analisando as informações complementares solicitadas e comparando-as com o que foi discutido na audiência, teve-se como resultado que apenas o pedido de IC referente à compensação ambiental tinha relação com a audiência. A compensação ambiental consiste na obrigação imposta ao empreendedor, nos casos onde o empreendimento tem atividade com impacto ambiental significativo, de apoiar a implantação e manutenção de unidades de conservação da natureza integrantes do grupo de proteção integral. De acordo com a Lei Federal $n^{\circ}$ 9.985/2000 (BRASIL, 2000), o cálculo deverá conter os indicadores do impacto gerado pelo empreendimento e das características do ambiente a ser impactado. Nesse sentido, cumprimento a condicionante solicitada, a empresa Vale Fertilizantes realizou a compensação ambiental, sendo que o valor compensado foi de $\mathrm{R} \$$ 2.781.097,90. O empreendedor apresentou um 
ofício do Núcleo de Compensação Ambiental atestando que a empresa quitou o referido valor.

Assim, pode-se verificar que apesar do intenso envolvimento popular em ternos de número de pessoas na audiência pública, com o levantamento de questões pertinentes que deveriam ser averiguadas, esta não resultou em nenhuma contribuição para o processo decisório. Isto vem de encontro ao apontado por MPF (2004): são raros os casos em que, após a realização de audiências públicas ou comentários referentes aos estudos, o órgão ambiental competente atende todas as exigências legais, que posteriormente não são adicionadas e nem submetidas a uma nova consulta pública do mesmo modo que fora realizado a audiência pública.

Em 27/04/2016, o Conselho Estadual de Política Ambiental (COPAM) concedeu a empresa Vale Fertilizantes a licença de instalação corretiva (LIC) para o projeto de Patrocínio. Portanto, a partir de junho de 2016, foi dada sequência à implementação da empresa e no dia 23/12/2016, a Vale Fertilizantes realizou a primeira expedição férrea de minério de fosfato para o Complexo Mineroquímico de Araxá. Esta ação marcou o início das atividades do projeto na cidade de Patrocínio.

O caso estudado reafirma situações já pontadas por Tambellini (2012), que considera que, na audiência pública, a sociedade não tem poder decisório, mas somente consultivo, ainda que possa determinar a necessidade de maiores aprofundamentos de questões assinaladas nas discussões pelos participantes; por Partidário e Sheate (2013), que afirmam que a participação pública, muitas vezes, limita-se a uma consulta pontual, realizada apenas como parte de uma obrigação legal; e por Almeida (2013) ao dizer que são raríssimos os casos que a participação consegue realmente intervir na tomada de decisão final, exercendo, portanto, em grande parte, uma função meramente consultiva ou informativa.

A efetiva participação do público deve envolver consultas via comunicação bidirecional entre o desenvolvedor do estudo ambiental ou empreendedor e o público e entre o órgão ambiental ou de Governo e as comunidades locais (Petts, 1999). Assim, considera-se fundamental que se encontre meios de realmente envolver a população afetada e os interessados, a fim de que estes atores possam trazer contribuições para o processo, ao invés da participação se restringir às audiências públicas, onde eles apenas recebem informações sobre o empreendimento (Almeida, 2013).

\section{Conclusão}

A ocorrência da participação pública dentro do processo de AIA no âmbito da SUPRAM TMAP foi baixa, pois dos 79 empreendimentos que foram licenciados com base na elaboração de um EIA/Rima entre 2009 e 2015, apenas 14 apresentaram a realização da audiência pública.

Com relação ao estudo de caso, mesmo a audiência pública relacionada ao empreendimento da Vale Fertilizantes tendo sido realizada e envolvido grande quantidade de participantes, esta não foi capaz de trazer nenhuma interferência no processo decisório, uma vez que as questões levantadas não resultou nem em pedido de informação complementar.

Assim, percebeu-se que a participação nos processos de licenciamento no âmbito da SUPRAM TMAP, quando ocorre, tem um poder restrito de influenciar a tomada de decisão. Logo, ela pode ser considerada como frágil, necessitando de aperfeiçoamentos.

\section{Referências}

Almeida, M.R.R., 2013. Aplicação da abordagem sistêmica para análise da efetividade da Avaliação de Impacto Ambiental no Brasil: um estudo para os estados de São Paulo e Sul de Minas Gerais. Tese (Doutorado). São Carlos, USP.

Almeida, M.R.R., Montaño, M., 2015. Benchmarking na Avaliação de Impacto Ambiental: o sistema mineiro frente às melhores práticas internacionais. Sociedade \& Natureza 27, 81-96.

Almer, H.L., Koontz, T.M., 2004. Public hearings for EIAs in post-communist Bulgaria: do they work? Environmental Impact Assessment Review 24, 473-493.

Bordenave, E.J.D., 1994. O que é participação. Brasiliense, São Paulo.

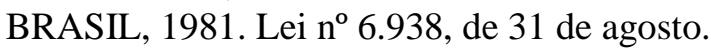

BRASIL, 1988. Constituição da República Federativa do Brasil.

BRASIL, 2000. Lei 9985, de 18 de julho.

Burian, P.P., 2006. Do estudo de impacto ambiental à avaliação ambiental estratégica: ambivalências do processo de licenciamento ambiental do setor elétrico. Tese (Doutorado). Campinas, UNICAMP.

CONAMA. Conselho Nacional do Meio Ambiente, 1987. Resolução ${ }^{\circ}{ }^{\circ}$ 009, de 03 de dezembro.

CONAMA. Conselho Nacional do Meio Ambiente, 1997. Resolução $n^{\circ}$ 237, de 19 de dezembro.

COPAM. Conselho Estadual de Política Ambiental, 1994. Deliberação Normativa ${ }^{\circ} 12$ de 13 dezembro. 
Cortner, H.J., 2000. Making sciene relevant to environmental policy. Environmental Science and Policy 3, 21-30.

Devlin, J.F., Yap, N.T., 2008. Contentious politics in environmental assessment: blocked projects and winning coalitions. Impact Assessment and Project Appraisal 26, 17-27.

Dias, E.G.C.S., Sánchez, L.E., 1999. A participação pública versus os procedimentos burocráticos no processo de avaliação de impactos ambientais de uma pedreira. Revista de Administração Pública 33, 81-91.

Furia, L.D., Wallace-Jones, J., 2000. The effectiveness of provisions and quality of practices concerning public participation in EIA in Italy. Environmental Impact Assessment Review 20, 457-479.

Glasson, J., Therivel, R., Chadwick, A., 2005. Introduction to Environmental Impact Assessment, 4 ed. Routledge, London.

Hartley, N., Wood, C., 2005. Public participation in environmental impact assessment: implementing the Aarhus Convention. Environmental Impact Assessment Review 25, 319-340.

Hokkanen, P., Jantunen, J., 2012. A multi-view evaluation of the Finnish EIA system: an 18year success story? Journal of Environmental Assessment Policy and Management 14, 1-22.

IAIA. International Association for Impact Assessment, 2006. Public Participation: International Best Practice Principles. Special Publication Series n. 4. Fargo, USA.

Kolhoff, A.J., Runhaar, H.A.C., Driessen, P.P.J., 2009. The contribution of capacities and context to EIA system performance and effectiveness in developing countries: towards a better understanding. Impact Assessment and Project Appraisal 27, 271-282.

Marcatto, F.S., 2005. A participação pública na gestão de área contaminada: uma análise de caso baseada na Convenção de Aarhus. Dissertação (Mestrado). São Paulo, USP.

Morgan, R.K., 2012. Environmental impact assessment: the state of the art. Impact Assessment and Project Appraisal 30, 5-14.

Morrison-Saunders, A., Early, G., 2008. What is necessary to ensure natural justice in environmental impact assessment decisionmaking? Impact Assessment and Project Appraisal 26, 29-42.

MPF. Ministério Público Federal, 2004. Deficiências em Estudos de Impacto Ambiental: síntese de uma experiência. Brasília.

Nadeem, O., Hameed, R., 2008. Evaluation of environmental impact assessment in Pakistan.
Environmental Impact Assessment Review 28, 562-571.

Ortolano, L., 1997. Environmental regulation and impact assessment. John Wiley and Sons, New York.

Panigrahi, J. K., Amirapu, S., 2012. An assessment of EIA system in India. Environmental Impact Assessment Review 35, 23-36.

Pardo, M., 1997. Environmental Impact Assessment: myth or reality? Lessons from Spain. Environmental Impact Assessment Review 17, 123-142.

Partidario, M.R., Sheate, W.R., 2013. Knowledge brokerage-potential for increased capacities and shared power in impact assessment. Environmental Impact Assessment Review 39, 26-36.

Petts, J., (1999). Public participation and environmental impact assessment, in: Petts, J. (Ed), Handbook of Environmental Impact Assessment, Vol. 1. Environmental Impact Assessment: Process, Methods and Potential. Blackwell Science, Oxford, pp. 145-177.

Pope, J., Bond, A., Morrison-Saunder, S.A., Retief, F., 2013. Advancing the theory and practice of impact assessment: setting the research agenda. Environmental Impact Assessment Review 41, 1-9.

Ronza, C., 1998. A política de meio ambiente e as contradições do Estado, a avaliação de impacto ambiental em São Paulo. Dissertação (Mestrado). Campinas, UNICAMP.

Sánchez, L.E., 1993. Avaliação de impacto ambiental: situação atual e perspectivas. Epusp, São Paulo.

Sánchez, L.E., 2008. Avaliação de impacto ambiental: conceitos e métodos. Oficina de Textos, São Paulo.

Sánchez, L.E., 2013. Avaliação de impacto ambiental: conceitos e métodos. Oficina de Textos, São Paulo.

Shepherd, A., Bowler, C., 1997. Beyond the requirements: improving public participation in EIA. Journal of Environmental, Planning and Management 40, 725-738.

Soneryd, L., 2004. Environmental Conflicts and Deliberative Solutions? A case study of public participation in EIA in Sweden. Örebro University Press, Örebro.

Steinemann, A., 2001. Improving alternatives for environmental impact assessment. Environmental Impact Assessment Review 21, 3-21.

Tambellini, A.T., 2012. Sobre o Licenciamento Ambiental no Brasil, país - potência emergente. Ciência \& Saúde Coletiva 17, 1399-1406. 
Revista Brasileira de Geografia Física v11, n.02 (2018) 510-520.

Vasconcelos, C., Hamilton, A., Barrett, P., 2000. Public participation in EIA: A study from a Portuguese perspective. Journal of
Environmental Assessment Policy and Management 2, 561-582.

World Bank, 1999. Environmental assessment sourcebook update. Washington. 